\title{
O LÚDICO NA EDUCAÇÃO INFANTIL: A DANÇA E IMAGINÁRIO NAS AULAS DE EDUCAÇÃO FÍSICA
}

\section{ARTIGO DE REVISÃo}

SILVA, Érica Jacira de Araújo ${ }^{1}$

SILVA, José Ernando de Farias ${ }^{2}$

SILVA, Érica Jacira de Araújo. SILVA, José Ernando de Farias. O lúdico na educação infantil: A dança e imaginário nas aulas de Educação Física. Revista Científica Multidisciplinar Núcleo do Conhecimento. Ano 04, Ed. 07, Vol. 09, pp. 127-138. Julho de 2019. ISSN: 2448-0959

\section{RESUMO}

O presente artigo buscou trazer algumas reflexões sobre o lúdico e sua importância na Educação Infantil aliada ao conteúdo dança na Educação Física. Estudos afirmam esta importância no desenvolvimento cognitivo, físico e emocional das crianças $O$ trabalho aborda, sucintamente, as discussões sobre infância, ludicidade, Dança e Educação Infantil, sobretudo no que diz respeito à questão da aprendizagem de que forma é concebida neste ciclo. A ludicidade é uma forma prazerosa de aprender, brincando reconhecendo-o o corpo de si e do outro, a dança traz a expressão natural de cada individuo criando seu próprio mundo.

1 Especialista em Educação Física escolar e infantil, Especialista em gestão e coordenação pedagógica (Faculdade Venda Nova do Imigrante-FAVENI) Licenciada em Educação Física- Centro universitário tabosa de almeida -ASCES/UNITACaruaru-PE).

${ }^{2}$ Especialista em História do Brasil (FIP/PB) Pós-graduando em História social e contemporânea (PROMINAS)- Possui graduação em História - Faculdades Integradas de Patos (2013). 
Palavras Chaves: Corpo, lúdico, dança, educação infantil, educação física.

\section{INTRODUÇÃO}

Buscando compreender como a dança deve ser trabalhada na Educação Infantil, não apenas como coreografia em eventos festivos da escola, mas como conteúdo da Educação Física, onde prioriza o desenvolvimento físico e intelectual das crianças. Como tratar a dança de forma pedagógica e lúdica no ambiente escolar? Sendo assim o seguinte problema da pesquisa foi: Como a ludicidade e Educação Infantil, devem contribuir no imaginário da dança nas aulas de Educação Física.

Segundo Brasileiro (2008) A dança, conhecimento presente no processo de escolarização brasileira, vai estar associada à inserção dos exercícios físicos, das ginásticas, pois será com a implementação da tríade educação moral, intelectual e física que veremos a entrada da dança nesse conjunto de conhecimentos necessários à educação das crianças e jovens brasileiros.

Para Verderi (2000), a Dança, associada à Educação Física, deverá ter um papel fundamental enquanto atividade pedagógica e despertar no aluno uma relação concreta sujeito-mundo. Deverá propiciar atividades geradoras de ação e compreensão, favorecendo a estimulação para ação e decisão no desenrolar das mesmas, para assim, poder modificá-las frente a algumas dificuldades que possam aparecer e através dessas mesmas atividades, reforçar a autoestima, a autoconfiança e o autoconceito.

Considerando a importância desta temática, espera-se que este trabalho possa contribuir na ampliação de discussões sobre o trato lúdico da dança na Educação Infantil nas aulas de Educação Física com um aparato pedagógico e prazeroso de ensino.

\section{LUDICIDADE, PARA QUE? IMAGINEI DANCEI}

Para dar início as discussões percebe-se que é necessário trazer a questão da ludicidade na Educação Infantil, como aprender de forma lúdica num mundo em 
construção partindo desta ideia ludicidade faz com que a criança aprenda com prazer, alegria e divertimento. Segundo Sneyders (1996, p.36) que "Educar é ir em direção à alegria."

[...] A Educação lúdica é uma ação inerente na criança e aparece sempre como uma forma transacional em direção a algum conhecimento, que se redefine na elaboração constante do pensamento individual em permutações constantes com 0 pensamento coletivo. [...] (ALMEIDA,1995,p.11).

Como fala o autor é de grande importância o trabalho lúdico pois traz o desenvolvimento global, meio as descobertas, criatividade onde a criança pode se expressar e transformar sua realidade. E preciso refletir sobre a importância da Educação lúdica, como ocorre este processo de ensinar e aprender na dança. Para a criança, brincar é se descobrir e viver, a brincadeira traz a emoção o reconhecimento de algo novo que ela gosta de conhecer.

A dança aliada a brincadeira tornar-se a Educação lúdica onde a criança desenvolve as suas próprias expressões, que não seja repetições de movimentos mais que esteja associado com a sua realidade cotidiana, dança com expressões de animais, contextualizando com a história de alguns personagens vivenciando um mundo de imaginário de descobertas.

Segundo Vygotsky (1984) atribui relevante papel ao ato de brincar na constituição do pensamento infantil. É brincando, dançando que a criança expressa seu estado cognitivo, visual, tátil, motor, seu modo de aprender entra em relação com o mundo e com as pessoas do seu convívio.

A criança brinca e desenvolve sua capacidade para determinado tipo de conhecimento, é no brincar que está um dos maiores espaços para formação de vários conceitos, é onde tudo se inicia o começo da autonomia e respeito entre os colegas.

Temos alguns documentos que norteiam a prática pedagógica um deles é o Referencial curricular da Educação Infantil (1998, p.23), onde afirma que Educar 
significa, portanto, propiciar situações de cuidados, brincadeiras e aprendizagens orientadas de forma integrada e que possam contribuir para o desenvolvimento das capacidades infantis de relação interpessoal, de ser e estar com os outros em uma atitude básica de aceitação, respeito e confiança.

Permitir o acesso, as crianças, aos conhecimentos mais amplos da realidade social e cultural. A dança e a brincadeira são experiências de vivencias prazerosas, a escola e o professor ao valorizar atividades lúdicas, ajudam a criança a formar um bom conceito do mundo em que a sociabilidade estimula as crianças.

Com o surgimento da Lei de Diretrizes e Bases da Educação Nacional - LDB (1996) passa-se a se concretizar objetivo principal da Educação Infantil que é desenvolver integralmente a criança até seis anos de idade, a fim de complementar a ação da família e da comunidade. A respeito do desenvolvimento integral infantil, o Plano Nacional para Educação (2000) afirma que o potencial humano deve ser explorado por profissionais capacitados a fim de promover o seu desenvolvimento sem desperdiçar suas habilidades.

Portanto é por meio das atividades lúdicas, e suporte de profissionais habilitados que a criança reproduz situações vividas em seu dia a dia, pela imaginação e pelo faz- de -conta são reelaboradas, experiências que se tornam de fundamental importância para o desenvolvimento da criança de forma lúdica na dança.

\section{EDUCAÇÃO FíSICA E DANÇA NA EDUCAÇÃO INFANTIL: RECONHECENDO O CORPO}

A arte a dança é a Educação Física, são disciplinas que exploram o sentir do ser, retirar essas disciplinas é negar uma existência da criatividade da cultural corporal, o que irá prejudicar bastante o desenvolvimento humano.

A atuação da dança, e o seu ensino em creches, pré-escolas visa proporcionar o desenvolvimento físico, social e emocional, além de promover os valores artísticoculturais. Segundo Santos, Lucarevski e Silva (2005), 
Devido aos métodos e processos livres utilizados por estas disciplinas, as crianças têm a possibilidade de aprender, pelas experiências do próprio corpo, a agirem livremente no espaço em que vivem interagirem com as pessoas que as cercam, além de expressarem sentimentos e pensamentos através de formas diferentes de comunicação corporal ( LUCAREVSKI e SILVA, 2005,p.1 - 2).

Como os autores pontuam a importância em promover a interação entre o 'eu' e o 'outro' estimulando a inteligência com este auxilio a dança se torna prazerosa, não um simples passo a ser decorado dar possibilidades da criança criar conceitos ao imaginar-se em diversas situações de interação e curiosidade com a dança e seu corpo.

Nesta perspectiva, é necessário que sejam traçados os objetivos, o brincar é importante sim, e deve ser visto como o desenvolvimento intelectual da criança que venha trazer possibilidade para sua formação.

A Educação Infantil é um período propicio para descoberta de si e do mundo onde criar-se e amplia-se as capacidades intelectuais. Godoy (2007) defende a importância de a dança ser vista na escola com espírito de investigação, levando a criança a compreender sua capacidade de movimento,

"entender melhor como seu corpo funciona, para que possa usá-lo expressivamente com inteligência, autonomia, responsabilidade e sensibilidade. Essa linguagem é uma forma de integração e expressão individual e coletiva, em que o aluno exercita a atenção, a percepção, a colaboração e a solidariedade. Como atividade lúdica permite a experimentação e criação no exercício da espontaneidade (GODOY, 2007, p. 7)."

Como expressa a fala do autor a criança deve compreender a capacidade de seus movimentos e a dança, Educação Física promover esta cultura corporal, deve-se pensar de modo que a criança e a experiência infantil conduzam este processo 
articulado com o professor, proporcionando momentos de educação do corpo que transgridam e superam a inculcação de um modelo ideal, da procura por rendimento e da competitividade, que seja algo prazeroso que não intimide o desenvolvimento das crianças.

Portanto é necessária uma dança que não aprisione o movimento, mas liberte a criatividade, a imaginação, a expressão corporal ( andar, correr, saltar, parar, girar) trabalhando as possibilidades dos movimentos e da consciência corporal, brincando com o corpo e reconhecendo-o. Para Marques (2010) A dança é um tipo de linguagem artística, é um sistema de signos que permite a comunicação por meio do corpo e do movimento. Sendo assim significa que ela possui um conjunto organizado de elementos com possibilidades de combinação que produzem significado, porém devemos lembrar que está comunicação na educação infantil não deve ser padronizada.

Contudo as crianças pequenas encontram-se ainda no processo de apropriação da fala, que caracteriza como imitativa, por isto utilizam-se das emoções para transmitir seus desejos seus sentimentos, nesta fase é importante o contato com a dança, pois, é onde o professor explora-la os sentidos criando um saber importante para o crescimento da criança.

Nesta perspectiva a dança, associada à Educação Física, deve ter um papel fundamental enquanto atividade pedagógica e despertar no aluno uma relação concreta sujeito-mundo. Compreender o corpo por meio da dança, como possibilidade de estabelecer múltiplas relações com outras áreas do conhecimento multidisciplinar.

Como apontado anteriormente percebemos a importância da dança, para o desenvolvimento infantil, porém temos um grande desafio trazer isto como lazer aliada a aprendizagem na época que estamos com os celulares e desenho com grande entretenimento de forma fácil e cômoda para nossas crianças, requer planejamento pedagógico, algo que fique atrativo e que seja de aprendizagem. 


\section{APRENDER DANÇANDO, DANÇAR PARA QUE?}

A dança traz inúmeros benefícios ao ser humanos vários autores, defendem seu beneficio pedagógico como também para saúde Marques (1997), assinala que na dança também estão contidas as possibilidades de compreendermos, desvelarmos, problematizarmos, e transformarmos as relações que se estabelecem em nossa sociedade entre etnias, gêneros, idades, classes sociais e religiões. Os Parâmetros Curriculares Nacionais (MEC, 1998), afirmam que a criança na escola convive com a diversidade e poderá aprender com ela.

Uma das barreiras do ensino da dança é a falta de conhecimento do professor e a carência de materiais e espaço adequado para trabalhar a dança na escola, apontadas pelos professores como limitações para trabalhar esse conteúdo nas aulas de Educação Física, foram abordados em estudos Pereira (2009), Sousa (2010), anteriores.

A literatura fala sobre a falta de preparo na formação de professores para trabalhar a dança de forma pedagógica, segundo Marques(1997) a formação de professores que atuam na área de dança é sem dúvida um dos pontos mais críticos no que diz respeito ao ensino desta arte em nosso sistema escolar, não tendo conhecimento suficiente para a práxis.

Contudo percebe-se a importância de tratar o lúdico ligando a atividade do dia a dia, fica uma aprendizagem prazerosa e divertida Para Wallon (1975) explica que as ações cotidianas de andar, correr, saltar, são atividades dinâmicas ligadas a necessidade de experimentar o corpo para o domínio dos movimentos e para a construção da autonomia.

O ensino de dança na escola pode dar subsídios ao aluno para melhor compreender, desvelar, desconstruir, revelar e transformar as relações que se estabelecem entre corpo, arte e sociedade, de forma a contribuir para que os alunos tomem consciência de suas potencialidades, aumentando sua capacidade de resposta e sua habilidade de 
comunicação. Seu objetivo englobaria a sensibilização e a conscientização tanto nas posturas, atitudes, gestos e ações cotidianas, quanto em suas necessidades de se expressar, comunicar, criar, compartilhar, interagir na sociedade em que vivemos (GODOY IN GODOY \& ANTUNES, 2010, p.39).

Como mencionado por Godoy a Educação Infantil é a base da Educação do reconhecimento do mundo, o que gosto de brincar, ou de fazer irá formando a personalidade e de grande importância o trato da dança nas aulas de Educação física nesta faixa etária, onde ocorre as interações que as crianças estabelecem sejam de cooperação, brincadeira ou confronto, elas aprendem a solucionar problemas, agir nos diferentes contextos, lugares, tamanho do grupo e objetos disponíveis .

A dança na educação infantil deve permitir que as crianças compreendam suas ações particulares e coletivas através da linguagem corporal, visto que a exteriorização dos sentimentos humanos também se dá pelo movimento. Concordamos que, nesta faixa etária, o trabalho corporal em dança não deve priorizar uma técnica padronizada por limitar os movimentos das crianças. (SILVEIRA; LEVANDOSKI; CARDOSO, 2008)

Destaca-se a necessidade de estudos que ofereçam aos profissionais da Educação Infantil conhecimentos para uma prática pedagógica sobre a cultura do movimento adequada à pequena infância, oriunda de situações concretas de ensinoaprendizagem dentro das realidades possíveis.

\section{A DANÇA NA SALA DE AULA: PLANEJAR É IMPORTANTE}

É necessário pontuar alguns critérios a) o tipo de dança- popular, folclórica, contemporânea; b) faixa etária c)música d) possibilidade dos movimentos grau de dificuldade e facilidade e) objetos e vestimentas f) segurança do espaço organizado g)Participação da família h) Mobilização de outros profissionais da instituição. 
Ressalta-se a importância da cooperação de diversos profissionais, para torna-se um projeto interdisciplinar pode-se trabalhar além da dança. Com história, ciências e português, e trazer diversas temáticas, ou seja, aprender brincando.

O caminho para chegar a maturidade adulta começa na infância, valores, crenças a autodescoberta corporal se constroem nesta fase sendo assim, os estímulos visuais, tátil, afetivo e motor, desenvolvidos na dança, são fundamentais para formação e integração social das crianças (VERDERI,1999;GOMES,2007;TREVISAN,2006). Como a autor afirma a formação das crianças o imaginário e o lazer deve ser explorado, a constante busca da alegria e do prazer em se movimentar através de movimentos ritmados e compassados, que desenvolve de forma criativa as diferentes funções mimicas e de expressões, é sem dúvida a melhor caracterização para dança e seus movimentos.

Desde a Educação infantil é importante adaptar criar propostas político- pedagógicas que vinculem a cultura escolar e as aprendizagens de origem externa da escolaridade, de acordo com a realidade vivenciada pelas crianças.

Para evitar exclusões entre meninos e meninas, o professor de Educação Física deve quebrar paradigmas e adaptar as aulas para todos os alunos, articulando ideias sobre diversos temas (CAPRI,2009).

Neste sentido, a dança se torna uma possibilidade para o desenvolvimento do lazer e do mundo imaginário nas escolas e nos espaços comunitários, principalmente seguindo um objetivo pedagógico, por meio de uma metodologia que valoriza a imaginação e a desconstrução de padrões de movimentos, onde o que importa é o processo de construção e não o produto final, proporcionando momentos de autoconhecimento, de satisfação e de prazer na criação o aprender brincando.

\section{PERCURSO METODOLÓGICO}

Para realização da pesquisa, através da abordagem qualitativa, por proporcionar uma aproximação maior com o campo investigado, possibilitando um contato direto do 
pesquisador com o fenômeno pesquisado, pois a mesma permite, durante o trabalho de investigação, a interação na relação dos que estão envolvidos na pesquisa.

Entre os mais diversos significados, conceituamos abordagem qualitativa ou pesquisa qualitativa como sendo um processo de reflexão através da utilização de métodos e técnicas para compreensão detalhada do objeto de estudo em seu contexto histórico e/ou segundo sua estruturação (OLIVEIRA, 2007, p. 37).

Tendo em vista a fala da autora, a abordagem qualitativa possibilita a realização da pesquisa contribuindo para seu entendimento, ofertando melhores caminhos para chegarmos na concretização dos resultados finais da pesquisa, utilizando-se da interação direta que ocorre entre pesquisador e campo pesquisado.

A análise dos dados se orientou pela análise de conteúdo, que busca através da inferência, captar os sentidos dos enunciados coletadas durante a pesquisa. $\mathrm{Na}$ perspectiva de Bardin (2008), ela pode ser definida da seguinte forma:

A análise de conteúdo pode ser considerada como conjunto de técnicas de análise de comunicações, que utiliza procedimentos sistemáticos e objetivos e descrições do conteúdo das mensagens. A intenção da análise de conteúdo é a inferência de conhecimentos relativos às condições de produção e de recepção das mensagens, inferência está que recorre a indicadores (quantitativos, ou não) (BARDIN, apud FRANCO, 2008, p. 24).

A análise de conteúdo permite ao pesquisador um contato mais denso com os dados coletados, refletindo sobre os mesmos a partir de todo o conhecimento vivenciado ao longo da pesquisa. Ela possibilita a percepção diante das questões que permeiam o problema da pesquisa, contribuído para que o pesquisador se aproxime ao máximo das questões colocadas pelo problema investigado.

Foram estes, portanto, os procedimentos metodológicos utilizados para a análise dos dados na pesquisa do trabalho. Mais do que apresentar respostas à questão central 
para o trabalho, procura uma maior aproximação com o contexto pesquisado e com o debate sobre o lúdico, a dança e o imaginário nas aulas de Educação Física, sobretudo a partir das novas questões surgidas ao longo da pesquisa.

\section{CONCLUSÃO}

Com o estudo foi possível reconhecer as diferentes possibilidades do ensino da dança na Educação Infantil nas aulas de Educação Física, aliada ao compromisso pedagógico, através de um ensino prazeroso onde o professor é a criança reconhecem um mundo e trocam ideias dentro das realidades vivenciadas.

Quanto as práticas pedagógicas na dança, ela não deve ser padronizada mais sim libertar de expressões, que façam a criança sentir quem ela realmente é, como ser existente, pensante e dançante.

Entendemos que a Dança e a Educação Física são campos bem abrangentes com inúmeras contribuições, que trabalhadas das melhores maneiras com a criança possibilitam a geração de capacidades e habilidades, além de trazer novos conhecimentos para serem apreendidos. As crianças encontram, não só por meio das brincadeiras, mas em todas as outras linguagens que realizam uma forma que torna real as impressões apreendidas em seu imaginário, sentindo-se livres para expressar seus mais fantásticos desejos.

Com a realização desse trabalho foi possível obter uma aproximação sucinta com o campo da ludicidade, dança e Educação física percebe-se como juntos podem beneficiar ainda mais no desenvolvimento das crianças, através dessa pesquisa traçamos alguns pontos dessa caminhada longa acerca desses campos tão significativos cheios de possibilidades.

\section{REFERÊNCIAS}

ALMEIDA, Anne. Recreação: ludicidade como instrumento pedagógico. 2009. Disponível em: <http://www.cdof.com.br/recrea22.htm>. Acesso em: 13 novembro 2017. 
ALMEIDA, Paulo Nunes de. Educação Lúdica: Técnicas e jogos pedagógicos. São Paulo: Loyola, 1995.

BRASIL. Ministério da Educação e do Desporto. Secretaria de Educação Fundamental. Referencial curricular nacional para a educação infantil. Brasília, 1998.v.2.

BRASIL. Ministério da Educação e do Desporto. Lei de Diretrizes e Bases da Educação Nacional. Lei n9.394, de 20 de dezembro de 1996. Brasília, 1996.

BRASIL, Ministério da Educação e do Desporto. Plano Nacional de Educação.Disponívelem:<ftp://ftp.fnde.gov.br/web/fnde/plano_nacional_educacao.pd $f>$. Acesso em: 03 de novembro de 2017.

BRASIL. Secretaria de Educação Fundamental. Parâmetros curriculares nacionais: arte / Secretaria de Educação Fundamental. - Brasília-DF : MEC/SEF, 1997.

BRASILEIRO, Lívia Tenorio .O ensino da dança na Educação Física: formação e intervenção pedagógica em discussão. Motriz, Rio Claro, v.14 n.4, p.519-528, out./dez. 2008

BROUGÈRE, G. Brinquedo e cultura. 3. ed. São Paulo: Cortez, 2000.

CAPRI,F.S. Rompendo as barreiras do gênero masculino: Prática da dança em aulas de Educação Física. Revista digital efdeportes.com, Buenos Aires, ano 14,n.136,set.2009.

FRANCO, Maria Laura Puglisi Barbosa. Análise de Conteúdo. Brasília, $3^{a}$ edição. Líber Livro Editora, 2008.

GODOY, K. M. A,ANTUNES, R. C. F. S.(orgs.). Movimento e Cultura na Escola: Dança. São Paulo. Instituto de Artes da Unesp, 2010. 
GODOY, K. M. A.O espaço da dança na escola. In: KERR, D. M. (org.). Pedagogia Cidadã: Caderno de formação: artes. São Paulo. Páginas \& Letras Editora e Gráfica, Unesp. Pró-Reitoria de Graduação, 2007.

GARANHANI, M. C. Os saberes de educadoras da pequena infância sobre o movimento do corpo infantil. In: CONGRESSO BRASILEIRO DE CIÊNCIAS DO ESPORTE E CONGRESSO INTERNACIONAL DE CIÊNCIAS DO ESPORTE, 14., 2005, Porto Alegre. Anais... PortoAlegre: CBCE, 2005.

MARQUES, Isabel A. Dançando na escola. Revista Motriz, v. 3, n. 1, p. 20-28, jun. 1997.

MARQUES, Isabel a. linguagem da dança: arte e ensino. São Paulo: digitexto, 2010. $239 p$

OLIVEIRA, Z. M. R. Educação Infantil: fundamentos e métodos. São Paulo: Cortez, 2010.

OLIVEIRA, Maria Marly de. Como fazer pesquisa qualitativa. Petrópolis: Vozes, 2007

SANTOS, Santa Marli Pires dos. Brinquedos e infância: um guia para pais e educadores. Rio de Janeiro: Vozes, 1999.

SNEYDERS, Georges. Alunos felizes. São Paulo: Paz e terra,1996.

SANTOS, J.; LUCAREVSKI, J. SILVA, R. M.. Dança na Escola - Benefícios e Contribuições na Fase Pré-Escolar. Centro Universitário Filadélfia - UniFil (Brasil).2005.

VYGOTSKY, L.S. A formação social da mente. São Paulo: Martins Fontes, 1984.

VYGOTSKY, L. S. Pensamento e linguagem. São Paulo: Martins Fontes, 1987.

VERDERI,É.B.L.P. Dança na Escola e ludicidade. Rio de Janeiro:Sprint,1998. 
VERDERI, É. B. L. P. Encantando a Educação Física. $2^{a}$ ed. Rio de Janeiro: Sprint, 2002.

VERDERI, E. B. L. P. Dança na Escola . 2ª ed. Rio de Janeiro: Sprint, 2000.

WALLON, H. Psicologia e Educação da Infância. São Paulo: Estampa, 1975

Enviado: Janeiro, 2019.

Aprovado: Julho, 2019. 